\title{
O fortalecimento da autoestima de adolescentes em escola pública
}

\section{Strengthening adolescents' self-esteem in public schools}

\author{
${ }^{1}$ Simone Domingues Garcia sidomingues@yahoo.com.br \\ ${ }^{1}$ Alessandra Crystian Engles dos Reis \\ ${ }^{1}$ Ana Carolina Moritz \\ ${ }^{1}$ Jaqueline Tokarski \\ ${ }^{1}$ Vanessa Cappellesso Horewicz
}

\section{RESUMO}

Este estudo tem por objetivo retratar atividade educativa supervisionada, de um grupo de acadêmicas de Enfermagem de uma universidade pública, ao trabalhar o tema autoestima com escolares adolescentes. Trata-se de um relato de experiência, durante a prática supervisionada da disciplina de Prática de Ensino I com acadêmicas de Enfermagem. Foi planejada uma atividade com o tema autoestima, direcionada a alunos dos sextos, sétimos e oitavos anos. Essa atividade foi dividida em quatro momentos. No início, os escolares responderam a Escala de Autoestima de Rosenberg - EAR, posteriormente as acadêmicas abordaram conceitos referentes a autoestima, autoconhecimento, planos futuros, além de incentivar os adolescentes quanto ao desempenho escolar. Após o conteúdo teórico, os alunos participaram de uma dinâmica em que escreveram características positivas dos colegas da turma, e fixaram nas costas uns dos outros. Para finalizar, compartilharam em grupo seus projetos futuros. A estratégia utilizada favoreceu a percepção dos alunos sobre a necessidade de serem trabalhadas, atividades que favoreçam o suporte emocional do adolescente na escola e, consequentemente, a autoestima. Para as graduandas foi uma oportunidade de desenvolverem a prática docente de forma sistematizada, abordando uma problemática complexa e pertinente para ser aplicada no ambiente escolar, local com significativa concentração de adolescentes que possuem convivência diária.

Palavras-chave: Prática de Ensino. Educação em Saúde. Escolares.

\section{ABSTRACT}

This study aims to portray a supervised educational activity, of a group of nursing students from a public university, working on the self-esteem theme with adolescent students. This is an experience report during the activity supervised of the Teaching Practice I discipline with Nursing students. An activity on the self-esteem theme aimed at students of the sixth, seventh and eighth years was planned. This activity was divided into four moments. At the beginning, the students answered the Rosenberg Self-Esteem Scale - EAR, later the students approached concepts related to self-esteem, self-knowledge, future plans, besides encouraging the adolescents regarding their school performance. After the theoretical content students participated in a dynamic in which they wrote positive characteristics of classmates, and fixed them on each other's backs. Finally, they shared their future projects as a group. The used strategy favored the students perception about the need to be worked, activities that favor the emotional support of the adolescent in the school and, consequently, the selfesteem. For the undergraduate students, it was an opportunity to develop their teaching practice in a systematic way, addressing a complex and pertinent problem to be applied in the school environment, a place with a significant concentration of adolescents who coexist daily.

Keywords: Teaching Practice. Health Education. School.

1 Universidade Estadual do Oeste do Paraná-Unioeste. 


\section{INTRODUÇÃO}

A adolescência é um período de transição do estado infantil para o estado adulto, com características singulares e problemas específicos (LUZ et al., 2018). Esse processo é marcado pelo desenvolvimento fisiológico, psicológico e social (PIGOZI; MACHADO, 2015) e é nesta fase que os indivíduos iniciam a maturação cognitiva, podendo apresentar alterações comportamentais/humor/irritabilidade e sociais, o que acaba por interferir em sua autopercepção, autoconceito e autoestima (CRUZ; SANTOS; RODRIGUES, 2016). É nessa fase que o sujeito busca construir sua individualidade, desencadeando dúvidas, medos, frustrações e descobertas, e consequentemente apresentar instabilidade emocional, que pode acarretar na tomada de atitudes autodestrutivas, entre elas a negligência com sua saúde (FONSECA et al., 2013).

Em relação à definição, “A Organização Mundial da Saúde apresenta como adolescente a pessoa com idade entre 10 e 19 anos, e jovens indivíduos entre 15 e 24 anos” (BRASIL, 2017, p. 07), enquanto o Artigo $2^{\circ}$ da Lei $n^{\circ}$ 8.069, que dispõe sobre o Estatuto da Criança e do Adolescente (ECA), descreve como adolescente o sujeito a partir dos 12 até os 18 anos (BRASIL, 1990). O Artigo $3^{\circ}$ desta mesma Lei, complementa que “[...] a criança e o adolescente gozam de todos os direitos fundamentais inerentes à pessoa humana, sem prejuízo da proteção integral [...]” (BRASIL, 1990, p. 1).

O ECA é considerado marco legal nacional e subsidia a efetivação da atenção integral à saúde de adolescentes e jovens (BRASIL, 2017). Contudo, apesar do adolescente no Brasil ter legislação própria que visa resguardar sua integridade, ser adolescente nesse país, é estar vulnerável por fatores multideterminados, com possível comprometimento social e psicológico, e consequentemente danos à saúde (CARMO; GUIZARDI, 2018). Fatores como, uso de drogas, violência, trabalho e exploração sexual infantil, gravidez precoce, entre outros, contribuem para a vulnerabilidade de crianças e adolescentes em nosso país (FONSECA et al., 2013). Salienta-se que para alguns autores, a utilização do "[...] termo vulnerabilidade amplia a compreensão dos múltiplos fatores que fragilizam os sujeitos no exercício de sua cidadania” (CARMO; GUIZARDI, 2018, p. 01).

A inserção do profissional de saúde na escola possibilita um olhar externo sobre o escolar. Não possuir vínculos com o aluno, pode significar neutralidade e não invasão da privacidade para o adolescente. Neste contexto, com a pretensão de compartilhar a vivência acadêmica prática, a qual pode ser replicada em outras realidades, com possíveis benefícios para os envolvidos, este relato tem como objetivo retratar a experiência de atividade educativa supervisionada, de um grupo de acadêmicas de Enfermagem Bacharelado e Licenciatura, de uma universidade pública, ao trabalhar o tema Autoestima com escolares adolescentes.

\section{METODOLOGIA}

Este estudo caracteriza-se como relato de experiência, realizado durante a disciplina de Prática de Ensino I de um grupo de acadêmicas do terceiro ano do curso de Enfermagem Bacharelado e Licenciatura de uma Universidade Estadual do Oeste do Paraná. Destaca-se, conforme as Resoluções do Conselho Nacional de Saúde nº 466 e n ${ }^{\circ} 510$, por ser este artigo um relato de experiência provindo de atividade educativa, e não atividade de pesquisa, configura a dispensa de apreciação de um Comitê de Ética em Pesquisa (BRASIL, 2012; BRASIL, 2016).

A atividade educativa foi planejada e executada sob supervisão docente com o tema Autoestima, além de abordar possibilidades futuras, como projetos de vida com os estudantes. Assim, justifica-se a abordagem qualitativa, na qual os pesquisadores analisam os dados de forma indutiva (FLICK, 2009), e do tipo descritivo, que consiste em descrever as características de fatos ou fenômenos de determinada população (MARCONI; LAKATOS, 2007).

A experiência aconteceu em uma escola pública da periferia de um município paranaense, com escolares do Ensino Fundamental II, dos quais, 70 eram dos sextos anos, 75 dos sétimos e 66 dos oitavos, totalizando um 
público de 211 alunos, entre meninos e meninas. A atividade educativa se deu em um período de 4 dias, sendo 2 horas-aulas por turma.

Foram realizadas abordagens expositivas e dialogadas em sala de aula, com uso de recursos audiovisuais, associadas a dinâmicas de grupo, denominadas Características Positivas da Turma ${ }^{2}$ e Projetos de Vida ${ }^{3}$, além da utilização de vídeo intitulado "Vídeo motivacional eleito o melhor 2015/2016”“ . Ocorreu também a atividade educativa por meio da aplicação da Escala de Autoestima de Rosenberg - EAR (1965) ${ }^{5}$, “[...] difundida em 53 países e adaptada para o Brasil” (SCIBIGO; BANDEIRA; DELL’AGLIO, 2010, p. 395).

Os escolares preencheram a EAR no início das atividades, a qual também foi adaptada pelas acadêmicas, conforme o Quadro 1, com as seguintes opções de resposta: concordo totalmente; concordo; discordo e discordo totalmente, em que cada item variou de 1 a 4 pontos. Salienta-se que a adaptação realizada pelas acadêmicas foi relacionada a elaboração das questões, ou seja, as opções de respostas com as respectivas pontuações foram preservadas. Assim, uma pontuação abaixo de 15 significou uma autoestima baixa, entre 15 e 25 uma autoestima saudável e acima de 25 refletiu em ótima autoestima. Em caso de dúvidas durante o preenchimento as acadêmicas auxiliaram os estudantes esclarecendo as questões e ajudando a preencher, respeitando os princípios éticos de não influenciar nas respostas e obtendo clareza da compreensão dos alunos ao auxiliá-los.

Após o preenchimento, foram discutidos os resultados obtidos com os escolares e realizada a exposição da fundamentação teórica do tema pelas acadêmicas, com espaço para discussão e esclarecimento para os estudantes.

\section{Quadro 1 - Adaptação da Escala de Autoestima de Rosenberg}

\begin{tabular}{|ll|}
\hline a) & De uma forma geral, estou satisfeito (a) comigo mesmo (a). \\
\hline b) & Às vezes, eu acho que eu não sirvo para nada ou sou inferior em relação aos outros. \\
\hline c) & Eu sinto que eu tenho um tanto de boas qualidades. \\
\hline d) & Eu sou capaz de fazer coisas tão bem quanto a maioria das outras pessoas (desde que me ensinadas). \\
\hline e) & Não sinto satisfação nas coisas que realizei. Eu sinto que não tenho muito do que me orgulhar. \\
\hline f) & Às vezes, eu realmente me sinto inútil (incapaz de fazer as coisas). \\
\hline g) & Eu sinto que sou uma pessoa de valor. \\
\hline h) & Não me dou o devido valor. Gostaria de ter mais respeito por mim mesmo (a). \\
\hline i) & Quase sempre eu estou inclinado (a) a achar que sou um (a) fracassado (a). \\
\hline j) & Eu tenho uma atitude positiva (pensamentos, atos e sentimentos positivos) em relação a mim mesmo (a) \\
\hline
\end{tabular}

Fonte: SCIBIGO, BANDEIRA, DELL'AGLIO, 2010.

Após a aplicação da escala e posterior discussão, desenvolveu-se a dinâmica Características Positivas da Turma $^{6}$ com a escrita de características positivas dos alunos em post-it ${ }^{\circledR}$ e fixados nas costas de cada colega de sala, com o objetivo de promover autoestima e o entrosamento da turma, a qual será descrita na próxima seção.

2 Disponível em: https://www.youtube.com/watch?v=seYR861XpRc

3 Elaborada pelo grupo de acadêmicas e professoras.

4 Disponível em: https://www.youtube.com/watch?v=IAnzAWt5tCI

5 Justifica-se o uso dessa Escala (elaborada nos Estados Unidos), pois é frequentemente utilizada nas pesquisas relacionadas a autoestima. Exemplo:

a) Formiga, NS; et al. Transtorno no uso do álcool e autoestima: verificação de um modelo empírico em diferentes grupos sociais. Mudanças Psicologia da Saúde, 22 (1) 9-19, Jan.-Jun., 2014. DOI: http://dx.doi.org/10.15603/2176-1019/mud.v22n1p9-19

b) Pechorro, P. Delinquência juvenil: Estudo de algumas variáveis psicológicas e relacionais com ênfase nos traços psicopáticos. Tese de Doutoramento, Universidade de Lisboa, Portugal, 2011.

c) Santos, MFT. Cyberbullying na adolescência: perfil psicológico de agressores, vítimas e observadores. Mestrado Integrado em Psicologia. Secção de Psicologia Clínica e da Saúde. Núcleo de Psicoterapia Cognitiva-comportamental e Integrativa. Universidade de Lisboa, 2015.

6 Disponível em: https://www.youtube.com/watch?v=seYR861XpRc 
Concluiu-se a atividade educativa com uma segunda dinâmica, elaborada pelas acadêmicas, denominada Futuro dos Adolescentes e seus Projetos de Vida, que teve por objetivo estimular planos profissionais e projetos pessoais, por meio de reflexões de suas vivências na escola, no intuito de ir além de disciplinas, visualizando, por exemplo, a disciplina de Ciências inserida em sua rotina, juntamente com a Matemática, Português, História, Geografia, entre outras. Os alunos eram divididos em grupos de em média 10 participantes, em que compartilhavam entre si seus anseios profissionais e eram convidados a projetar sua imaginação dez anos no futuro, associando ao que gostavam na escola. Todos os grupos tinham a participação de uma acadêmica que estimulava o compartilhamento de ideias, para que entre eles pudessem pensar em diferentes possibilidades. Por fim, finalizava-se as atividades com a apresentação do "Vídeo motivacional eleito o melhor 2015/2016"7 .

Os professores das turmas que estavam responsáveis pela classe no momento da atividade foram convidados a participarem de todas as atividades, assim permaneceram nas turmas durante a execução, já que as acadêmicas eram acompanhadas por uma docente de Prática de Ensino.

\section{RESULTADOS E DISCUSSÃO}

\section{A prática educativa na escola}

Optou-se por discutir as atividades de acordo com a ordem cronológica em que foram desenvolvidas, para que seja didaticamente possível ao leitor compreender a importância de cada etapa do planejamento.

Inicialmente com a aplicação da Escala de Autoestima foi possível oportunizar aos alunos alguns pontos de reflexão referente ao autoconhecimento, a partir de um roteiro de questões que abordou: como se dá a visão de si mesmo; como se sentem em relação aos outros e como se sentem consigo mesmo e suas potencialidades. O resultado da pontuação média obtida a partir da aplicação da escala foi de: 30,2 pontos nos sextos anos, 28,4 pontos nos sétimos anos e 26,4 pontos nos oitavos, equivalendo, conforme a EAR, uma autoestima satisfatória.

Posteriormente, apresentou-se a fundamentação teórica abrangendo a autoestima na adolescência e a sua influência no projeto de vida, os adolescentes participaram de forma positiva com questionamentos dessa fase vivenciada por eles. Para esse momento foi utilizada a aula expositiva dialogada com auxílio de recursos audiovisuais, aparelho datashow e caixa de som. Foi um momento importante para proporcionar a compreensão do estudante relacionada a autoestima em todo seu desenvolvimento, não somente na vida escolar, mas também pessoal, abordando como se sente enquanto ser social, que interage, convive e expressa sentimentos e ideias. São poucas as oportunidades que os adolescentes e jovens tem para refletirem sobre questões próprias, para pensarem em seus projetos de vida de acordo com os desejos e necessidades (BRASIL, 2017).

Em seguida, foi utilizada a dinâmica Características Positivas da Turma7, na qual os escolares colocaram post-it ${ }^{\circledR}$ nas costas uns dos outros, e andaram na sala durante esse processo para escreverem qualidades aleatórias de cada colega, sem que o mesmo visualizasse, enquanto tocava a música Try, de Colbie Caillat, estimulando-os a interagirem. Ao término da música, os alunos retiraram seus respectivos post-it ${ }^{\circledR}$ e leram as qualidades a eles designadas. Terminada essa dinâmica foi discutida a importância da valorização pessoal. Todos os alunos participaram e foi frisado a importância de pensarem que todos possuem características positivas, reforçando que enquanto grupo eles podem estimular uns aos outros de diferentes formas, como com elogios e reforçando potencialidades. Com a leitura do que foi colocado em cada papel houve a manifestação de diferentes emoções com certo espanto, por não esperarem aquelas características. Foi percebido entusiasmos, risos e aparente satisfação pessoal. Os professores das turmas eram convidados a participarem dessa dinâmica e escreverem também

7 Disponível em: https://www.youtube.com/watch?v=seYR861XpRc 
nos post-it ${ }^{\circledR}$ dos alunos, o que foi algo positivo e interessante de observar, a empolgação dos alunos com a participação dos professores.

A dinâmica dos post-it ${ }^{\circledR}$ pode ser considerada um dos pontos principais desenvolvidos com os estudantes, já que foi um momento de descontração e interação entre eles na sala de aula, com a oportunidade de elogiarem-se uns aos outros. As acadêmicas de enfermagem destacaram que todos possuíam características positivas, e os incentivaram para a importância de se olharem, assim, também, para se elogiarem uns aos outros. Os elogios destacados pelos estudantes foram: inteligente, companheiro, amigo, bom jogador de futebol, parceiro, bonito, entre outros.

Ao realizarem a leitura das características descritas pelos colegas de classe no final da dinâmica, pôde-se observar que a turma estava mais integrada. Percebeu-se que ao escreverem características positivas de cada um, os alunos conseguiram pensar em adjetivos que não imaginavam neles mesmos.

Neste contexto, é importante salientar também o papel do professor ao elogiar o aluno, pois quando esse ressalta as qualidades dos alunos reforça sua autoestima (D’ÁVILA; VEIGA, 2014). Em pesquisa sobre diferenças interativas e comunicativas realizada por Barroso et al. (2017) foi percebido que durante a dinâmica de interação entre mãe/filho e educadora/criança a comunicação elogiosa contribui para o desenvolvimento da autoestima e da autoimagem. Para a finalização da atividade educativa foi proposta a dinâmica Futuro dos Adolescentes e seus Projetos de Vida, para tanto formaram-se dois círculos na mesma sala, com os escolares sentados em suas cadeiras, ou seja, dois grupos mistos de meninos e meninas, cada grupo com uma acadêmica ao centro, a qual questionou: “onde você se imagina daqui 10 anos?”. Considerou-se a atividade positiva e relevante para fechar a proposta inicial de abordar a autoestima, e até os estudantes mais tímidos expressaram seus anseios e pararam para pensar no futuro, já que não é algo que ocorre rotineiramente. Os professores que participaram dessa atividade estimularam os escolares a falarem, ressaltando características que já conheciam nos seus alunos.

Percebeu-se que algumas profissões que foram citadas tinham associação com algumas disciplinas do conhecimento dos alunos, como por exemplo gostar de ciências e desejar ser médico veterinário, gostar de matemática e pensar em engenharia. Houve poucas citações quanto a profissões relacionadas a licenciatura, talvez, devido aos alunos partirem do senso comum, que há pouca valorização, inclusive financeira, além do desgaste emocional.

Também foi percebido durante a atividade educativa quanto a importância do significado do momento vivenciado por cada estudante na escola, para que esse momento o impulsione a ir além dos muros da instituição de ensino, e imaginar quais as ferramentas necessárias para que possa sonhar e planejar. Destaca-se que a forma como o indivíduo determina o valor de si influencia diretamente em como ele projeta suas expectativas para o futuro.

Tal projeção pode ser denominada projeto de vida, que se origina da interação entre a identidade pessoal e autoestima, pela busca por conquista de melhorias pessoais e oportunidades, sendo influenciado pelo contexto interno e fortemente pelo contexto externo, devido às relações sociais, condições financeiras e culturais (BRASIL, 2010). O projeto de vida expressa as direções centrais dos sujeitos, determinando sua posição e pertencimento a sociedade, assim, seus valores e perspectivas irão definir suas prioridades (VERNI; TARDELI, 2016).

Em estudo realizado por Farre et al. (2018) considerou-se, que em áreas urbanas, os adolescentes necessitam de autodeterminação para superar barreiras econômicas e enfrentar riscos sociais no sentido de transcorrer o período de vida de forma positiva, e todos esses fatores podem influenciar de forma significativa para a formulação de futuros projetos. Desse modo, a adolescência é um período crucial de transição, que precisa ser acompanhado pela família, escola, serviços de saúde e sociedade.

Foi destacado aos escolares, que o reconhecimento de suas próprias qualidades e de seu valor enquanto cidadão é importante para estabelecer planos de vida. Essa estratégia de valorização individual foi percebida pelas 
acadêmicas como conduta importante a ser adotada pela escola, a fim de favorecer a autoestima dos alunos, que se apresentaram motivados após a realização das atividades propostas, percebido em suas falas e comportamentos.

No decorrer da dinâmica Futuro dos Adolescentes e seus Projetos de Vida alguns propósitos citados pelos alunos foram relacionados a sonhos profissionais, sendo o desejo de seguir a profissão do pai ou da mãe e exemplos de sucesso profissional dentro da família que serviam de motivação para seguir a mesma profissão. Também foi significativo o número de alunos que almejava ingressar na universidade, contudo, os alunos destacaram a inserção em instituições privadas pela necessidade de trabalharem concomitante com seus estudos, o que mostra a compreensão da realidade social e econômica dos alunos daquela região. Entende-se que, em geral, não há um conhecimento concreto acerca das condições de se estudar na universidade pública, pois a mesma pode oferecer estágios, projetos, dentre outras possibilidades de permanência. Além disso, os alunos, desconsideraram o fato de as mensalidades serem pagas, no caso das instituições particulares. Observa-se a construção social da ideia de que o acesso à universidade privada é favorável aos estudantes economicamente prejudicados, enquanto que o acesso à universidade pública é difícil de ser concretizado.

Referente a família e a influência do comportamento dos pais no desenvolvimento dos adolescentes, considera-se que quando essas relações não são bem construídas podem influenciar nos comportamentos antissociais, uso de substâncias, depressão e autoestima inadequada dos adolescentes. Em contrapartida, o clima familiar afetivo, com responsividade, propicia a proteção dos filhos de riscos e o favorecimento do desenvolvimento global saudável. Ressalta-se que quanto mais positivas as práticas educativas dos pais, melhor a autoestima dos filhos. É importante lembrar que a relação familiar gera influência em ambos, pais e filhos (WEBER, 2017).

As acadêmicas, durante suas atividades de prática de ensino, tiveram papel fundamental ao estimularem os escolares com pensamentos a respeito de possibilidades de vivências que envolviam superação, rompimento de barreiras impostas por eles mesmos e pela família. Nesse contexto, foi observado em alguns relatos que os alunos participantes das atividades demonstraram que após a finalização do ensino médio existiriam poucas oportunidades para eles, o que foi logo problematizado pelas acadêmicas para que acreditassem além da realidade posta naquele momento.

Com isso, é possível compreender a importância da autoestima, que equivale à forma que o indivíduo se percebe e se aceita em diversos momentos de sua vida, partindo dos valores por ele adquiridos e vivenciados como bons ou ruins, podendo ser em diferentes contextos sociais e grupos de interação (SCHULTHEISZ; APRILE, 2013).

Houve relatos de alguns escolares que desejavam viajar, ter casa própria e constituir família. Destacam-se também alunos que expressaram a respeito do desejo de seguirem carreiras virtuais, comumente chamadas de influenciadores digitais, por considerarem, segundo eles, ser um caminho mais fácil para adquirir um alto poder aquisitivo.

Com a popularização da internet e o uso de diferentes ferramentas virtuais como as redes sociais emerge uma nova forma de comunicação e outros tipos de anseios, levando os jovens a terem pertencimento e reconhecimento imediatos como integrantes deste fenômeno. Os chamados influenciadores, de certa forma, criam seus públicos em torno de gostos e opiniões específicas (CAMARGO; ESTEVANIM; SILVEIRA, S/D).

Pela análise das atividades de prática de ensino desenvolvidas pelas acadêmicas foi possível perceber que a discussão dos projetos de vida e suas diferentes possibilidades, juntamente com a valorização da autoestima, transformou o espaço escolar em algo agregador, oportunizando novos olhares às disciplinas, maior interação da turma e a possibilidade de projeções de novos sonhos pelos alunos participantes.

Referente a sequência de atividades realizadas, foi possível observar que há aceitação de atividades lúdicas e dinâmicas que esclareçam dúvidas. Isso é corroborado pelo estudo de Lacerda et al. (2017), compartilhado também com o público de adolescentes, os quais referiram que dinâmicas e diferentes atividades são estratégias 
satisfatória para a redução das inquietações e a autorreflexão em temas importantes para essa faixa etária. O espaço para o diálogo entre estudantes incentiva o aprendizado, tornando-o mais atrativo e colabora para que os mesmos o socializem posteriormente (LACERDA et al., 2017).

\section{CONSIDERAÇÕES}

Foi perceptível que trabalhar a autoestima dos adolescentes na escola é essencial para o bem-estar e a autopercepção dos adolescentes, já que esse é um tema de relevância e de pouca abordagem tanto no âmbito familiar quanto escolar. É interessante que os profissionais da saúde, preferencialmente, os enfermeiros, envolvam-se e utilizem a educação em saúde como estratégia para a formação e o desenvolvimento de comportamentos saudáveis entre os escolares.

Apesar de a adolescência estar contemplada nas políticas públicas, essa fase exige atenção e dedicação dos sujeitos que compartilham com o adolescente seus espaços, como a família e educadores. A adolescência constitui-se em um período de vulnerabilidade diante das adaptações cognitivas e físicas, podendo emergir nessa fase comportamentos de risco à integridade da saúde.

No relato referente às atividades de prática de ensino das acadêmicas do curso de licenciatura e bacharelado em Enfermagem foi possível notar que a atuação das mesmas na promoção da saúde em uma determinada comunidade escolar favoreceu a comunicação e a empatia com os estudantes. Ou seja, ao expor e instigar a reflexão do tema eleito adotou-se uma atitude sensível, receptiva e dinâmica por parte das acadêmicas e professores no processo de desenvolvimento da atividade, a fim de proporcionar a compreensão sobre condutas positivas em relação a si mesmo e ao futuro dos alunos

Ao trabalhar a temática analisou-se a importância do elogio para o incentivo da autoestima, em especial na vida do adolescente, o qual passa por um período de mudanças físicas e comportamentais, por vezes, interferindo no cotidiano, nas relações com os outros, consigo mesmo e com o próprio futuro.

No relato também ficou evidente a percepção social do adolescente referente a sua formação profissional, quando opta pela universidade privada à pública, justificando sua necessidade de trabalho. Observa-se que o estudante não se sente apto e que o acesso facilitado a instituição privada é entendido como um caminho para a sua formação profissional. Neste caso, a falta de informação a respeito do ingresso nas universidades públicas e da existência de programas que visam a permanência de alunos nessas instituições pode influenciar os planos para o futuro do adolescente.

No que tange a autoestima, quando aplicada a EAR foi percebido escore com significância adequada para os adolescentes, resultado que favorece seu convívio social, sua saúde e planos futuros. Contudo, esse escore tem o decréscimo com a idade dos estudantes, o que pode sugerir uma crescente insatisfação com a própria imagem.

Nesse sentido, considera-se fundamental que a escola aborde as potencialidades dos estudantes para que se sintam estimulados e valorizados em seu desenvolvimento pessoal e escolar, abrangendo ações concretas de promoção a saúde do escolar. 


\section{REFERÊNCIAS}

BARROSO, I. et al. Estudo sobre as diferenças interativas e comunicativas das educadoras e das mães com crianças em idade pré-escolar. Da Investigação às Práticas, v. 7, n. 1, pp. 41-62, 2017.

BRASIL. Ministério da Saúde. Secretaria de Atenção à Saúde. Departamento de Ações Programáticas e Estratégicas. Proteger e cuidar da saúde de adolescentes na atenção básica [recurso eletrônico], Brasília: Ministério da Saúde, 2017.

BRASIL. Ministério da Saúde. Conselho Nacional de Saúde. Resolução nº 510, de 07 de abril de 2016. Brasília, 2016. Disponível em: < http://conselho.saude.gov.br/images/comissoes/conep/documentos/NORMASRESOLUCOES/Resoluo_n_510_-_2016_-_Cincias_Humanas_e_Sociais.pdf $>$. Acesso em 19 Jan. 2019.

BRASIL. Ministério da Saúde. Resolução nº 466, de 12 de dezembro de 2012. Brasília, 2012. Disponível em: < http://bvsms.saude.gov.br/bvs/saudelegis/cns/2013/res0466_12_12_2012.html>. Acesso em 19 Jan. 2019.

BRASIL. Ministério da Saúde. Secretaria de Atenção em Saúde. Departamento de Ações Programáticas Estratégicas. Diretrizes nacionais para a atenção integral à saúde de adolescentes e jovens na promoção, proteção e recuperação da saúde. Brasília: Ministério da Saúde, 2010.

BRASIL. Lei No 8.069, de 13 de julho de 1990. Dispõe sobre o Estatuto da Criança e do Adolescente e dá outras

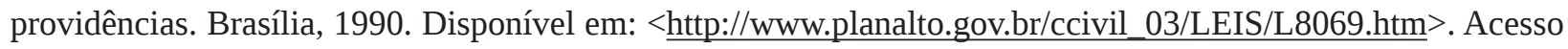
em: 19 Jan. 2019.

CAMARGO, I.; ESTEVANIM, M.; SILVEIRA S. C. Cultura participativa e convergente: o cenário que favorece o nascimento dos influenciadores digitais. Revista Communicare, v. 17, Ed. Esp. de 70 anos da Faculdade Cásper Líbero, S/D.

CARMO, M. E.; GUIZARDI, F. L. O conceito de vulnerabilidade e seus sentidos para as políticas públicas de saúde e assistência social. Cad. Saúde Pública, Rio de Janeiro, v. 34, n. 3, 2018. Disponível em: <http://www. scielo.br/pdf/csp/v34n3/1678-4464-csp-34-03-e00101417.pdf>. Acesso em: 29 Jan. 2019.

CRUZ, M.; SANTOS, L. R.; RODRIGUES, L. P. O autoconceito e auto-estima de adolescentes praticantes de modalidades náuticas. Psic., Saúde \& Doenças, Lisboa, v. 17, n. 3, pp. 389-402, 2016. Disponível em: <http:// www.scielo.mec.pt/pdf/psd/v17n3/v17n3a07.pdf>. Acesso em: 29 Jan. 2019.

D’ÁVILA, C. M.; VEIGA, I. P. A. Profissão docente: novos sentidos, novas perspectivas. Papirus Editora, 2014.

FARRE, A. G. M. C. et al. Adolescent health promotion based on community-centered arts education. Rev Bras Enferm [Internet], v. 71, n. 1, pp. 26-33, 2018. DOI: http://dx.doi.org/10.1590/0034-7167-2016-0078.

FLICK, U. Métodos de Pesquisa: introdução à pesquisa qualitativa. 3ª Ed. Porto Alegre: Artmed, 2009.

FONSECA, F. F. et al. As vulnerabilidades na infância e adolescência e as políticas públicas brasileiras de intervenção. Rev Paul Pediatr, São Paulo, v. 31, n. 2, pp. 258-264, Jun. 2013. Disponível em: < http://www. scielo.br/pdf/rpp/v31n2/19.pdf>. Acesso em: 19 Jan. 2019.

LACERDA E. D. et al. Gravidez na adolescência ações lúdicas no Ensino Médio: relato de experiência do projeto de extensão. Cienc Cuid Saude, v. 16, n. 2, 2017.

LUZ, R. T. et al. Saúde mental como dimensão para o cuidado de adolescentes. Rev. Bras. Enferm. Brasília, v. 71, supl. 5, pp. 2087-2093, 2018. Disponível em: <http://www.scielo.br/pdf/reben/v71s5/pt_0034-7167-reben71-s5-2087.pdf>. Acesso em: 26 Jan. 2019. 
MARCONI, M. A.; LAKATOS, E. M. Fundamentos de metodologia cientifica. São Paulo: Atlas, 2007.

PIGOZI, P. L.; MACHADO, A. L. Bullying na adolescência: visão panorâmica no Brasil. Ciênc. saúde coletiva, Rio de Janeiro, v. 20, n. 11, pp. 3509-3522, 2015. Disponível em: <http://www.scielo.br/pdf/csc/v20n11/14138123-csc-20-11-3509.pdf>. Acesso em: 19 Jan. 2019.

SCHULTHEISZ, T. S. De V.; APRILE, M. R. Autoestima, conceitos correlatos e avaliação. Rev. Equilíbrio Corporal e Saúde, São Paulo, v. 5, n. 1, pp. 36-48, 2013. Disponível em: < http://www.pgsskroton.com.br/seer/ index.php/reces/article/view/22/19>. Acesso em: 29 Jan. 2019.

SCIBIGO, J. B.; BANDEIRA, D. R.; DELL'AGLIO, D. D. Escala de Autoestima de Rosenberg (EAR): validade fatorial e consistência interna. Psico-USF, v.15, n.3, pp. 395-403, 2010. Disponível em: < www.scielo.br/pdf/ pusf/v15n3/v15n3a12.pdf >. Acesso em: 24 Jan. 2019.

VERNI, P. J.; TARDELI, D. D. Autoestima e projeto de vida na adolescência. In: Association for Moral Education Conference Proceedings. In: 41st Association For Moral Education Conference. Universidade de São Paulo, pp. 1-12, 2016. Disponível em: <http://www.fecilcam.br/revista/index.php/anaisame/article/ viewFile/1353/841>. Acesso em: 8 Ago. 2019.

WEBER, L. N. D. Relações entre práticas educativas parentais percebidas e a autoestima, sinais de depressão e uso de substâncias por adolescentes. International Journal of Developmental and Educational Psychology, v. 2, n. 1, pp. 157-168, 2017. 